\title{
BMJ Open Predictors of skilled attendance at delivery among antenatal clinic attendants in Ghana: a cross-sectional study of population data
}

\author{
Mary Amoakoh-Coleman, ${ }^{1,2}$ Evelyn K Ansah, ${ }^{3}$ Irene Akua Agyepong, ${ }^{4}$ \\ Diederick E Grobbee, ${ }^{1}$ Gbenga A Kayode, ${ }^{1}$ Kerstin Klipstein-Grobusch ${ }^{1,5}$
}

To cite: AmoakohColeman M, Ansah EK, Agyepong IA, et al. Predictors of skilled attendance at delivery among antenatal clinic attendants in Ghana: a cross-sectional study of population data. BMJ Open 2015:5:e007810. doi:10.1136/bmjopen-2015007810

- Prepublication history for this paper is available online. To view these files please visit the journal online (http://dx.doi.org/10.1136/ bmjopen-2015-007810)

Received 29 January 2015 Revised 9 March 2015 Accepted 18 March 2015

CrossMark

For numbered affiliations see end of article.

Correspondence to Mary Amoakoh-Coleman; menba19@yahoo.com

\section{ABSTRACT}

Objective: To identify demographic, maternal and community predictors of skilled attendance at delivery among women who attend antenatal clinic at least once during their pregnancy in Ghana.

Design: A cross-sectional study using the 2008 Ghana Demographic and Health Survey (DHS) data. We used frequencies for descriptive analysis, $\chi^{2}$ test for associations and logistic regression to identify significant predictors. Predictive models were built with estimation of area under the receiver operating characteristic curves (AUC).

Setting: Ghana.

Participants: A total of 2041 women who had a live birth in the 5 years preceding the survey, and attended an antenatal clinic having a skilled provider, at least once, during the pregnancy.

Outcome: Skilled attendance at delivery.

Results: Overall, $60.5 \%$ (1235/2041) of women in our study sample reported skilled attendance at delivery. Significant positive associations existed between skilled attendance at delivery and the variables such as maternal educational level, wealth status class, ever use of contraception, previous pregnancy complications and health insurance coverage $(p<0.001)$. Significant predictors of skilled attendance were wealth status class, residency, previous delivery complication, health insurance coverage and religion in a model with AUC $(95 \% \mathrm{Cl})$ of 0.85 (0.83 to 0.88$)$.

Conclusions: Women less likely to have skilled attendance at delivery can be identified during antenatal care by using data on wealth status class, health insurance coverage, residence, history of previous birth complications and religion, and targeted with interventions to improve skilled attendance at delivery.

\section{INTRODUCTION}

Risk of maternal death continues to be high in sub-Saharan Africa (SSA) and Southeast Asia compared with the more developed parts of the world. In 2008, maternal deaths in SSA and Southern Asia accounted for

\section{Strengths and limitations of this study}

- The use of nationally representative data that facilitates generalisability of results to pregnant women in Ghana.

- An assessment of a combination of factors that significantly predict skilled attendance at delivery which has not been done for the study setting.

- The Demographic and Health Survey (DHS) data are retrospectively collected data, and therefore has the chance of recall bias potentially affecting results.

- Only surviving mothers were interviewed and this could have affected the prevalence of the outcome.

- Our results are not applicable to the women who do not access antenatal care during pregnancy.

$87 \%$ of global maternal deaths and progress to reverse this, especially in SSA, has been slow. ${ }^{1-7}$ Efforts to encourage utilisation of healthcare facilities should also be vigorously pursued for optimal results.

A skilled attendant is defined as "an accredited health professional-such as a midwife, doctor or nurse-who has been educated and trained to proficiency in the skills needed to manage normal (uncomplicated) pregnancies, childbirth and the immediate postnatal period, and in the identification, management and referral of complications in women and newborns". ${ }^{8}$ Antenatal care and delivery by a skilled attendant both contribute to reduction in maternal deaths. ${ }^{10-17}$ The issue of who is a skilled attendant has been debated for some time, with respect to which category of health workers is 'skilled'. ${ }^{18}$ In Ghana, these are obstetricians, general practitioners, midwives, auxiliary midwives and nurses with midwifery training, including community health nurses/officers. ${ }^{19}$ There is also evidence that there are variations in these categories, with respect to the extent of training 
and roles in different countries across the world. ${ }^{20-22}$ Delivery by any other person (health worker or nonhealth worker) is termed 'unskilled attendance' at delivery.

Despite the body of evidence of the importance of skilled attendance at delivery, there are records of high antenatal attendance, but low skilled attendance at delivery, especially in developing countries. ${ }^{23-26}$ In Tanzania, over $90 \%$ of pregnant women are known to attend antenatal clinic (ANC) at least once, with $62 \%$ attending four times. However, less than $50 \%$ of these ANC attendants have their deliveries attended to by skilled personnel. ${ }^{3}$ In a study in Uganda, although ANC attendance was found to be as high as $94 \%$, this was not reflected in care at delivery, with about $25 \%$ of women being assisted during labour by a relative or friend. ${ }^{13}$

In Ghana, according to the 2008 Ghana Demographic and Health Survey (DHS), about $97 \%$ of pregnant women received antenatal care during pregnancy, with as many as $78.2 \%$ attending at least four times. However, only $57.1 \%$ delivered in health facilities, with a total of $59 \%$ being assisted by skilled personnel. ${ }^{19}$ Several reasons have been attributed to this pattern, including access to health facilities, health worker attitude towards women during delivery and cultural issues, among others. ${ }^{27}$

Some factors have also been quantitatively shown to be associated with skilled attendance at delivery. Maternal age is believed to influence the decision to take such an action, with younger women preferring skilled attendance at delivery due to perception of risk. ${ }^{28}$ This is closely linked with parity, where multiparous women with experience in labour tend to opt for other unskilled support during delivery due to the perception that they are experienced. Other factors such as marital status, wealth index, employment status and high educational background, especially secondary education, of both the woman and the husband has also been positively associated with the outcome. ${ }^{3}{ }^{23}$ Living in rural areas where poverty is more prevalent compared with urban areas has been shown to be negatively associated with skilled delivery. ${ }^{23-2629}$ Other notable factors that have positive influence on the outcome are short distance to health facility and availability of a birth-preparedness plan designed together with the woman during ANC. ${ }^{3}$

Many interventions have been implemented to improve maternal health in Ghana, including but not limited to the Safe Motherhood Initiative (SMI), free delivery policy, High Impact Rapid Delivery (HIRD) and the Emergency Obstetric and Neonatal Care programme. ${ }^{30-32}$ The free delivery fee policy was first introduced in four regions in 2003, and subsequently extended to the entire country in 2005. Some studies have so far been conducted in Ghana to identify factors that influence skilled attendance at delivery. ${ }^{33}{ }^{34}$ Secondary data analysis of Ghana DHS offers the opportunity to evaluate a larger sample across the country in order to identify demographic, maternal and community predictors of skilled attendance at delivery among women who attend ANC at least once during their pregnancy in Ghana. The question we seek to answer is whether there are possible significant predictors that will enable providers to identify women who are less likely to have skilled attendance at delivery from the antenatal care attendants, so that these women can be supported to have this desirable outcome. The aim of the study is to identify demographic, maternal, community and contextual predictors of skilled attendance at delivery among women who attend ANC at least once during their pregnancy.

\section{METHODS}

\section{Study design}

Secondary data analysis of the data set of the 2008 Ghana DHS, a nationally representative populationbased survey of 4305 women aged 15-49 years was conducted.

\section{Data collection}

Comprehensive information on the sampling techniques and survey procedures applied for data collection in the Ghana DHS have been published in detail elsewhere. ${ }^{35}$ In summary, the 10 regions of Ghana are each administratively subdivided into districts, while each district is divided into localities. Each locality is then further divided into enumeration areas based on the 2000 population census and these form the primary sampling units (PSUs). The PSU, defined for the purposes of this study as the cluster, was provided by the Ghana Statistical Service. A stratified two-stage cluster randomised sampling technique was applied. The first stage involved probability proportional sampling of a total of 412 PSUs (clusters) from all the regions, comprising of 182 clusters from the urban areas and 230 from rural areas. During the second stage, an average of 15 households was randomly sampled from each of the PSU using their household sampling frame. Finally, for half of the surveyed households, all eligible women aged 15-49 years were interviewed with a women's questionnaire. This had questions with socioeconomic, demographic and health indicators. Questionnaires were translated into three major local Ghanaian languages (Akan, Ga and Ewe) and were pretested on the field by trained personnel before finalisation for use. All respondents gave informed consent to participate in the survey. A total of 4916 women aged between 15 and 49 years were interviewed, with a $96.5 \%$ (4305) response rate. Out of these, the subset of women who had a live birth in the 5 years preceding the survey numbered 2099; 95.4\% (2041) of them did receive antenatal care from a skilled provider (doctor, nurse, midwife, auxiliary midwife or community health officer) in the health system. ${ }^{19}$ Characteristics of these 2041 women were assessed in this study.

The index delivery studied is the latest delivery within the 5 years preceding the survey. 
The 2008 DHS data are the latest available populationbased data on health indicators that address the objectives of this study. Another survey was due in 2013, but is yet to be conducted.

\section{Ethical approval}

Ethical approval to conduct DHS in Ghana was approved by the Ethics Committee of ICF Macro in Calverton, USA, and the Ethics Committee, Ghana Health Service, Accra, Ghana. We obtained ethics approval for analysis of this data from the Ethics Committee of ICF Macro in Calverton, USA through an online request.

\section{VARIABLES}

\section{Outcome}

Skilled attendance at delivery was the outcome. This in Ghana, and as used in the DHS data collection and analysis, is defined as delivery by a doctor, nurse, midwife, auxiliary midwife or community health officer, ${ }^{19}$ with a response of either yes (1) or no (0).

\section{Determinants}

The factors included in this study are based on findings from other studies in published literature and availability in the 2008 DHS data set. These were categorised as demographic, maternal, community and contextual factors. All the variables were put into building the models to avoid preselection. Table 1 shows all the variables and their definitions.

\section{Statistical analyses}

Total missing data were more than $5 \%$ and this level of missing data is rarely random. Thus, multiple imputations of missing data were conducted and analysis was based on the data set with imputed data. We carried out descriptive univariate analysis to evaluate the prevalence of delivery by a skilled provider (outcome variable)

Table 1 Definition of variables used in the study

\begin{tabular}{|c|c|}
\hline Variables & Description \\
\hline \multicolumn{2}{|l|}{ Demographic } \\
\hline Age & $\begin{array}{l}\text { Age (years and categories) at last delivery within } 5 \text { years preceding survey }(<20 \text {; } \\
20-34 ; \geq 35)\end{array}$ \\
\hline Highest educational level & Highest educational attainment (no education; primary; secondary and higher) \\
\hline Marital status & $\begin{array}{l}\text { Marital status as at interview date (never married; currently married; formerly } \\
\text { married) }\end{array}$ \\
\hline Ethnicity & $\begin{array}{l}\text { Local ethnic group (Akan; Ga/Dangme; Ewe; Guan; Mole-Dagbani; Grussi, } \\
\text { Gruma, other) }\end{array}$ \\
\hline Religion & Christian; Muslim; traditional/spiritualist; no religion and other \\
\hline Employment & Employment status as at interview date (currently employed (yes or no)) \\
\hline Wealth class status & Wealth quintiles categorised into three classes (low; middle; high)* \\
\hline Covered by health insurance & Having a viable health insurance registration (yes or no) \\
\hline \multicolumn{2}{|r|}{ 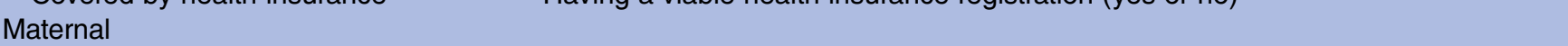 } \\
\hline Ever use of contraception & Use of any method of contraception at any point in time by woman (yes or no) \\
\hline Previous birth interval & $\begin{array}{l}\text { Number of years between last delivery and the preceding delivery }(<2 ; 2-5 ; 5+ \\
\text { years) }\end{array}$ \\
\hline Complication during previous delivery & $\begin{array}{l}\text { Whether woman had any complication during previous deliveries before last } \\
\text { delivery (DHS uses caesarian section as proxy) (yes or no) }\end{array}$ \\
\hline Birth order & $\begin{array}{l}\text { The order in which the index child, whose delivery data are used for our study, } \\
\text { was born: } 1 ; 2-3 ; 4-5 ; 6+\end{array}$ \\
\hline Gestational age at first ANC & Months pregnant at first ANC visit categorised into three trimesters of pregnancy \\
\hline Number of times attended ANC & $\begin{array}{l}\text { Number of times woman attended ANC during last pregnancy }(1 ; 2-3 ; 4+; \text { don't } \\
\text { know) }\end{array}$ \\
\hline \multicolumn{2}{|l|}{ Community and contextual } \\
\hline Region & $\begin{array}{l}\text { Where in the } 10 \text { regions of Ghana woman lives (Western; Central; Greater Accra; } \\
\text { Volta; Eastern ;Ashanti; Brong Ahafo; Northern; Upper East and West) }\end{array}$ \\
\hline Residence & Whether woman's residence is rural or urban \\
\hline Type of city & $\begin{array}{l}\text { Woman's residence described as capital or large city, small city; a town or country } \\
\text { side }\end{array}$ \\
\hline Spouse's highest educational level & Highest educational level of spouse (no education; primary; secondary and higher) \\
\hline Who has final say on woman's health & $\begin{array}{l}\text { Whose decision on woman's health is paramount (respondent alone; respondent } \\
\text { and partner; husband/partner/someone else alone) }\end{array}$ \\
\hline Period of delivery & $\begin{array}{l}\text { Whether last delivery was before or during the period of free cost of delivery, that } \\
\text { is, before or after } 2005\end{array}$ \\
\hline
\end{tabular}

*Wealth measured using information on household ownership of consumer items, ranging from a television to a bicycle or car, as well as dwelling characteristics, such as source of drinking water, sanitation facilities and type of flooring material to produce an asset index. ANC, antenatal clinic; DHS, Demographic and Health Survey. 
across the categories of each of the determinants. We regrouped wealth quintiles into low (poorest and poorer quintiles), middle (middle quintile) and high (richer and richest quintiles) wealth status classes due to small numbers in some of the quintile groups.

Bivariate analysis using $\chi^{2}$ test was used to investigate the relationship between the independent variables and the categorical outcome variable, with detection of significant differences at $\mathrm{p}<0.05$. We explored possible correlations between the variables region and birth order; region and religious groups; region and wealth status class; residence and wealth status class; and wealth status class and educational level.

Three predictive models were built using a backward stepwise elimination approach and all correlated variables were built into the models as interaction terms. Model 1 included the demographic and maternal characteristics; model 2 included the community and contextual factors; and model 3 combined demographics, maternal, community and contextual factors. Age was explored both as a categorical and continuous variable in building the models. Associations were estimated by ORs and their corresponding 95\% CIs. Each OR is adjusted for the other covariates in the model. The area under the curve (AUC), that is, under the receiver operating characteristic curves, for all the models were estimated.

\section{RESULTS}

\section{Background characteristics of the women}

Table 2 shows a summary of the characteristics of the 2041 women who for their latest delivery within the period of 2003 and 2008 had at least one ANC visit which was attended to by a health professional. The mean age (SD) of the women was 30 (7.24) years and this was the same for both groups of women who had skilled and unskilled attendance at delivery. As many as $89.0 \%$ of women were currently married during the survey and $86.8 \%$ of them were currently working. Only $41.4 \%$ of the women had secondary or higher education, and $35.3 \%$ had no education. Most of them were Christians $(68 \%)$ and $20.1 \%$ were Muslims. Wealth distribution among this population was $50.2 \%, 17.7 \%$ and $32.1 \%$ for low, middle and high wealth status classes, respectively. Only $42.8 \%$ of the women had health insurance coverage at the time of the survey. Prevalence of ever use of any contraceptive method among the women was $60.0 \%$. As many as $80.0 \%$ of women attended ANC at least four times during the pregnancy. Rural dwellers were $63.4 \%$.

Prevalence of skilled attendance at delivery was $60.5 \%$; most of the pregnant women were attended to by midwives and nurses (45.4\%). Doctors conducted only $9 \%$ of all deliveries.

\section{Comparability of the two outcome groups}

Table 2 also summarises the comparison between women who had skilled or unskilled attendance at delivery.
There were significant differences $(\mathrm{p}<0.05)$ between those having skilled and unskilled attendance among all the categories of the characteristics studied, except for period of delivery as per the free delivery policy ( $p=0.11$ ). Women with secondary and higher education had more skilled attendance at delivery compared with those without any education. About $67.0 \%$ of Christians had skilled attendance at delivery compared with $57.2 \%$ and $45.2 \%$ of Muslims and non-religious women, respectively. Women who had ever used a contraceptive method were more likely to have skilled attendance at delivery $(69.9 \%)$. The proportion of skilled attendance at delivery decreased with increasing birth order; $95.1 \%$ of women who had a caesarean section during their previous pregnancy had skilled attendance at delivery compared with $48.7 \%$ of those who did not have that complication. The outcome was more prevalent $(73.9 \%)$ among women with health insurance coverage compared with those without $(50.6 \%)$. There were regional variations in the proportion of women who had skilled attendance at delivery. Only $45.0 \%$ of women in rural areas had skilled attendance at delivery compared with $86.7 \%$ in urban areas. We checked for correlation among variables, and birth order and timing of first ANC attendance were significantly correlated $(\mathrm{p}<0.001)$. Wealth status class was significantly different among the categories of region, rural or urban settlements, and educational levels $(\mathrm{p}<0.001)$. Birth order and religious group categories also varied across the various regions $(\mathrm{p}<0.001)$. These correlations were explored as interaction terms in building the predictive models.

\section{Predictors of skilled delivery}

Three models for predicting skilled delivery among the women in the survey, using a backward stepwise approach, were built. These are shown in table 3. Model 1 consists of maternal factors and significant predictors were wealth quintile, history of previous delivery complication, having health insurance, birth order, number of times ANC was attended, the exact maternal age in years, religious group and ethnicity. Interaction terms explored were not significant predictors. Model 2 was built with community or cluster factors, and the significant predictors were residence (rural/urban), type of residence (capital/large city, small city and town or country side), spouse's highest educational level and the geographical region. In Model 3, demographic, maternal and community factors were combined. Significant predictors were wealth status class, history of previous birth complication, health insurance coverage, residence and religious group. Again in this model, interaction terms included were not significant. The predictive probabilities of all three models are (c-statistics $(95 \%$ CI) $) 0.85$ (0.82 to 0.88$) ; 0.80$ (0.78 to 0.82$)$ and 0.85 (0.83 to 0.88 ), respectively, for models 1,2 and 3 . Model 3 combines both groups of variables, has the least number of variables and also the best fit, making it the best among the three for use in practice. 
Table 2 Baseline characteristics of the study population and univariable associations of predictor variables with outcome

\begin{tabular}{|c|c|c|c|c|}
\hline Variable & $\begin{array}{l}\text { Frequency (\%) } \\
(\mathrm{N}=2041)\end{array}$ & $\begin{array}{l}\text { Per cent of unskilled } \\
\text { delivery }(\mathrm{N}=807)\end{array}$ & $\begin{array}{l}\text { Per cent of skilled } \\
\text { delivery }(N=1234)\end{array}$ & $\begin{array}{l}p \text { Value for } \\
\chi^{2} \text { test }\end{array}$ \\
\hline \multicolumn{5}{|l|}{ Demographic and maternal factors } \\
\hline Age (years) & & & & 0.05 \\
\hline$<20$ & $102(5.0)$ & 44.1 & 55.9 & \\
\hline $20-34$ & $1331(65.2)$ & 37.6 & 62.4 & \\
\hline$\geq 35$ & $608(29.8)$ & 42.9 & 57.1 & \\
\hline Highest educational level & & & & 0.00 \\
\hline No education & $720(35.3)$ & 60.8 & 39.2 & \\
\hline Primary & 476 (23.3) & 41.4 & 58.6 & \\
\hline Secondary and higher & 845 (41.4) & 21.6 & 78.4 & \\
\hline Marital status & & & & 0.04 \\
\hline Never married & $112(5.5)$ & 28.6 & 71.4 & \\
\hline Currently married & $1816(89.0)$ & 40.4 & 59.6 & \\
\hline Formerly married & $113(5.5)$ & 37.2 & 62.8 & \\
\hline Ethnicity & & & & 0.00 \\
\hline Akan & 806 (39.5) & 29.2 & 70.8 & \\
\hline Ga/Dangme & $96(4.7)$ & 38.5 & 61.5 & \\
\hline Ewe & $256(12.6)$ & 32.8 & 67.2 & \\
\hline Guan & $52(2.6)$ & 46.2 & 53.8 & \\
\hline Mole-Dagbani & $524(25.7)$ & 52.1 & 47.9 & \\
\hline Grussi & $111(5.4)$ & 43.2 & 56.8 & \\
\hline Gruma & $108(5.3)$ & 75.9 & 24.1 & \\
\hline Other & $86(4.2)$ & 25.6 & 74.4 & \\
\hline Religion & & & & 0.00 \\
\hline Christian & $1389(68.0)$ & 33.1 & 66.9 & \\
\hline Muslim & $410(20.1)$ & 42.8 & 57.2 & \\
\hline Traditionalist/spiritualist & $149(7.3)$ & 80.4 & 19.6 & \\
\hline No religion and other & $89(4.4)$ & 54.8 & 45.2 & \\
\hline Employment (currently working) & & & & 0.00 \\
\hline No & $269(13.2)$ & 33.3 & 66.7 & \\
\hline Yes & $1772(86.8)$ & 40.5 & 59.5 & \\
\hline Wealth status class & & & & 0.00 \\
\hline Low & $1024(50.2)$ & 60.7 & 39.3 & \\
\hline Middle & $361(17.7)$ & 30.7 & 69.3 & \\
\hline High & $656(32.1)$ & 11.3 & 88.7 & \\
\hline Ever use of contraception & & & & 0.00 \\
\hline No & $817(40.0)$ & 51.9 & 48.1 & \\
\hline Yes & $1224(60.0)$ & 30.1 & 69.9 & \\
\hline Previous birth interval (years) & & & & 0.00 \\
\hline$<2$ & $990(62.4)$ & 42.4 & 57.6 & \\
\hline $2-5$ & 236 (14.9) & 48.3 & 51.7 & \\
\hline $5+$ & $360(22.7)$ & 27.2 & 72.8 & \\
\hline Complication during previous delivery & & & & 0.00 \\
\hline No & $1920(94.1)$ & 51.3 & 48.7 & \\
\hline Yes & $121(5.9)$ & 4.9 & 95.1 & \\
\hline Birth order & & & & 0.00 \\
\hline 1 & $450(22.0)$ & 28.0 & 72.0 & \\
\hline $2-3$ & $753(36.9)$ & 35.7 & 64.3 & \\
\hline $4-5$ & $482(23.6)$ & 42.9 & 57.1 & \\
\hline $6+$ & $356(17.4)$ & 57.6 & 42.4 & \\
\hline Gestational age at first ANC & & & & 0.00 \\
\hline 1st trimester & $1179(57.8)$ & 34.2 & 65.8 & \\
\hline 2nd trimester & 807 (39.5) & 45.4 & 54.6 & \\
\hline 3rd trimester & $55(2.7)$ & 64.2 & 35.8 & \\
\hline Number of times ANC attended & & & & 0.00 \\
\hline 1 & $60(2.9)$ & 75.0 & 25.0 & \\
\hline $2-3$ & $293(14.3)$ & 65.9 & 34.1 & \\
\hline $4+$ & $1633(80.0)$ & 33.1 & 66.9 & \\
\hline Don't know & $55(2.7)$ & 52.7 & 47.3 & \\
\hline
\end{tabular}


Table 2 Continued

\begin{tabular}{|c|c|c|c|c|}
\hline Variable & $\begin{array}{l}\text { Frequency (\%) } \\
(\mathrm{N}=2041)\end{array}$ & $\begin{array}{l}\text { Per cent of unskilled } \\
\text { delivery }(\mathrm{N}=807)\end{array}$ & $\begin{array}{l}\text { Per cent of skilled } \\
\text { delivery }(N=1234)\end{array}$ & $\begin{array}{l}\text { p Value for } \\
\chi^{2} \text { test }\end{array}$ \\
\hline Covered by health insurance & & & & 0.00 \\
\hline No & $1167(57.2)$ & 49.4 & 50.6 & \\
\hline Yes & $874(42.8)$ & 26.1 & 73.9 & \\
\hline \multicolumn{5}{|l|}{ Community and contextual factors } \\
\hline Region & & & & 0.00 \\
\hline Western & $179(8.8)$ & 43.0 & 57.0 & \\
\hline Central & $145(7.1)$ & 37.2 & 62.8 & \\
\hline Greater Accra & $201(9.8)$ & 11.9 & 88.1 & \\
\hline Volta & $166(8.1)$ & 39.8 & 60.2 & \\
\hline Eastern & $178(8.7)$ & 33.7 & 66.3 & \\
\hline Ashanti & $310(15.2)$ & 23.9 & 76.1 & \\
\hline Brong Ahafo & $199(9.7)$ & 33.7 & 66.3 & \\
\hline Northern & $287(14.0)$ & 67.6 & 32.4 & \\
\hline Upper East & $172(8.5)$ & 52.3 & 47.7 & \\
\hline Upper West & $204(10.0)$ & 49.5 & 50.5 & \\
\hline Residence & & & & 0.00 \\
\hline Urban & $748(36.6)$ & 13.1 & 86.9 & \\
\hline Rural & $1293(63.4)$ & 54.8 & 45.2 & \\
\hline Type of city & & & & 0.00 \\
\hline Capital/large & $315(15.4)$ & 10.2 & 89.8 & \\
\hline Small & 263 (12.9) & 16.0 & 84.0 & \\
\hline Town & $468(23.0)$ & 29.5 & 70.5 & \\
\hline Country side & 995 (48.8) & 59.8 & 40.2 & \\
\hline Spouse's highest educational attainment & & & & 0.00 \\
\hline No education & $569(27.9)$ & 66.8 & 33.2 & \\
\hline Primary & $179(8.8)$ & 43.6 & 56.4 & \\
\hline Secondary and higher & 1293 (63.3) & 26.0 & 74.0 & \\
\hline Who has final say on woman's health & & & & 0.02 \\
\hline Respondent alone & $446(21.9)$ & 36.2 & 63.8 & \\
\hline Respondent and partner & $915(44.8)$ & 38.7 & 61.3 & \\
\hline Husband/partner/someone alone & $680(33.3)$ & 45.1 & 54.9 & \\
\hline Period of delivery & & & & 0.11 \\
\hline Before free delivery policy & 535 (26.2) & 36.6 & 63.4 & \\
\hline During free delivery policy & $1506(73.8)$ & 40.6 & 59.4 & \\
\hline
\end{tabular}

\section{Model fit statistics}

There was a significant increase in the c-statistic (AUC) estimates for model 3 compared with models 1 and 2. More importantly, there was a progressive increase in $\mathrm{R}^{2}$ value observed in model 1 when we fitted models 2 and 3. This implies that model 3 explains the predictors better and can, thus, be considered to be the most accurate model for application in clinical practice.

\section{DISCUSSION}

Main findings

The role of skilled attendance at delivery in averting maternal morbidity and mortality cannot be overemphasised as being the single most important intervention for safe motherhood. ${ }^{22} 36$

Highly educated women are significantly more likely to have skilled attendance at delivery compared with women with no education and previous studies have highlighted this finding. ${ }^{33}$ 37-39 This emphasises the importance of female education for achievement of Millennium Development Goal (MDG) 5. The relationship between cost and access to healthcare, specifically, maternal health services, has been explored in various studies and the summary of findings agrees with what we also found..$^{28} 4041$ Wealthier women in Ghana, as well as those with health insurance coverage, are more likely to have skilled delivery compared with poor women. Family planning services uptake is an important indicator for utilisation of maternal health services, ${ }^{42}{ }^{43}$ which leads to improved outcomes. ${ }^{44}$ In our study, ever use of contraception increases the chance of having skilled attendance at delivery. Utilisation of skilled attendants is also preventive and that is possibly why women who have had previous pregnancy complications prefer to have a skilled attendant for subsequent deliveries, and thus reduce their vulnerability.

On the community level, we observed previously noted rural-urban disparities. ${ }^{28} 40 \quad 45$ The opportunities for 
Table 3 Predictors of skilled attendance at delivery among pregnant women who attended ANC at least once during the pregnancy, Ghana Health and Demographic Survey, 2008

\begin{tabular}{|c|c|c|c|}
\hline Predictor & $\boldsymbol{\beta}$ & p Value & $\mathrm{OR}^{*}(95 \% \mathrm{Cl})$ \\
\hline \multicolumn{4}{|l|}{ Demographic and maternal factors (model 1) } \\
\hline \multicolumn{4}{|l|}{$A \cup C(95 \%$ CI) 0.85 (0.82 to 0.88$)$} \\
\hline \multicolumn{4}{|l|}{ Wealth status class } \\
\hline Low & $\dagger$ & $\dagger$ & $\dagger$ \\
\hline Middle & 1.34 & 0.00 & 3.82 (2.25 to 6.49$)$ \\
\hline High & 2.10 & 0.00 & $2.14(1.09$ to 4.20$)$ \\
\hline Complication during previous delivery (yes) & 2.16 & 0.00 & 13.53 (2.63 to 69.47$)$ \\
\hline Covered by health insurance (yes) & 1.10 & 0.00 & $3.00(1.98$ to 4.54$)$ \\
\hline \multicolumn{4}{|l|}{ Birth order } \\
\hline 1 & $\dagger$ & $\dagger$ & $\dagger$ \\
\hline $2-3$ & -0.30 & 0.24 & $0.74(0.45$ to 1.22$)$ \\
\hline $4-5$ & -0.88 & 0.02 & $0.42(0.21$ to 0.84$)$ \\
\hline Maternal age in years & 0.05 & 0.04 & 1.05 (1.00 to 1.09$)$ \\
\hline \multicolumn{4}{|l|}{ Religious group } \\
\hline Christian & $\dagger$ & $\dagger$ & $\dagger$ \\
\hline Muslim & -0.12 & 0.40 & $0.77(0.43$ to 1.40$)$ \\
\hline Traditionalist & -1.34 & 0.01 & 0.26 (0.10 to 0.67$)$ \\
\hline No religion/other & -0.52 & 0.28 & 0.60 (0.23 to 1.54$)$ \\
\hline \multicolumn{4}{|l|}{ Ethnicity } \\
\hline Akan & 1.00 & 0.02 & $2.72(1.14$ to 6.46$)$ \\
\hline Ga/Dangme & $\dagger$ & $\dagger$ & † - r t \\
\hline Ewe & 1.53 & 0.03 & $4.62(1.71$ to 12.53$)$ \\
\hline Guan & 0.43 & 0.60 & $1.55(0.30$ to 7.90$)$ \\
\hline Mole-Dagbani & 0.62 & 0.21 & $1.87(0.71$ to 4.94$)$ \\
\hline Grussi & 0.84 & 0.15 & $2.32(0.74$ to 7.30$)$ \\
\hline Gruma & 0.77 & 0.20 & $2.15(0.68$ to 6.86$)$ \\
\hline Other & 1.56 & 0.02 & $4.78(1.30$ to 17.56$)$ \\
\hline \multicolumn{4}{|l|}{ Community and contextual factors (model 2) } \\
\hline \multicolumn{4}{|l|}{$A \cup C(95 \% \mathrm{Cl}) 0.80$ (0.78 to 0.82$)$} \\
\hline Residence (rural) & -1.31 & 0.00 & $0.27(0.18$ to 0.41$)$ \\
\hline \multicolumn{4}{|l|}{ Type of city } \\
\hline Capital/large & 0.49 & 0.14 & $1.63(0.85$ to 3.10$)$ \\
\hline Small & $\dagger$ & $\dagger$ & $\dagger$ \\
\hline Town & 0.03 & 0.92 & $1.03(0.62$ to 1.70$)$ \\
\hline Country side & -0.66 & 0.01 & $0.52(0.31$ to 0.88$)$ \\
\hline \multicolumn{4}{|l|}{ Spouse's highest educational level } \\
\hline No education & -0.87 & 0.00 & $0.42(0.28$ to 0.63$)$ \\
\hline Primary & $\dagger$ & $\dagger$ & $\dagger$ \\
\hline Secondary and higher & 0.30 & 0.12 & $1.36(0.92$ to 1.99$)$ \\
\hline \multicolumn{4}{|l|}{ Region } \\
\hline Western & -1.53 & 0.60 & $0.86(0.49$ to 1.52$)$ \\
\hline Central & $\dagger$ & $\dagger$ & $\dagger$ \\
\hline Greater Accra & 0.24 & 0.53 & $1.27(0.60$ to 2.70$)$ \\
\hline Volta & 0.22 & 0.43 & $1.25(0.72$ to 2.19$)$ \\
\hline Eastern & 0.32 & 0.26 & $1.38(0.79$ to 2.42$)$ \\
\hline Ashanti & 0.50 & 0.06 & $1.65(0.97$ to 2.78$)$ \\
\hline Brong Ahafo & 0.47 & 0.09 & $1.61(0.93$ to 2.79$)$ \\
\hline Northern & -0.47 & 0.09 & $0.63(0.37$ to 1.08$)$ \\
\hline Upper East & 0.31 & 0.28 & $1.37(0.78$ to 2.41$)$ \\
\hline Upper West & 0.60 & 0.03 & $1.83(1.05$ to 3.17$)$ \\
\hline \multicolumn{4}{|c|}{ Demographic, maternal, community and contextual factors (model 3) } \\
\hline \multicolumn{4}{|c|}{$A \cup C(95 \% C l) 0.85$ (0.83 to 0.88$)$} \\
\hline \multicolumn{4}{|l|}{ (Interactions not significant in model) } \\
\hline \multicolumn{4}{|l|}{ Wealth status class } \\
\hline Low & $\dagger$ & $\dagger$ & $\dagger$ \\
\hline Middle & 0.63 & 0.04 & $1.88(1.02$ to 3.47$)$ \\
\hline High & 1.18 & 0.00 & 3.27 (1.60 to 6.68$)$ \\
\hline
\end{tabular}


Table 3 Continued

\begin{tabular}{|c|c|c|c|}
\hline Predictor & $\boldsymbol{\beta}$ & p Value & $\mathrm{OR}^{\star}(95 \% \mathrm{Cl})$ \\
\hline Residence (rural) & -1.31 & 0.00 & $0.27(0.14$ to 0.52$)$ \\
\hline Complication during previous delivery (yes) & 3.09 & 0.04 & 21.93 (2.61 to 184.04$)$ \\
\hline Covered by health insurance (yes) & 1.03 & 0.00 & 2.74 (1.83 to 4.30$)$ \\
\hline \multicolumn{4}{|l|}{ Religious group } \\
\hline Christian & 0.34 & 0.51 & $1.40(0.52$ to 3.76$)$ \\
\hline Muslim & -0.08 & 0.99 & 0.99 (0.34 to 2.87$)$ \\
\hline Traditionalist/spiritualist & -0.78 & 0.24 & $0.46(0.12$ to 1.70$)$ \\
\hline No religion/other & $\dagger$ & $\dagger$ & $\dagger$ \\
\hline
\end{tabular}

higher education and improved wealth status, among other factors, are undeniably few in rural areas ${ }^{46} 47$ and when these were adjusted for in the prediction model, women from rural areas still had less prevalence in the outcome. Perhaps other factors such as geographical access to healthcare are at play here, but the data we used did not allow us to explore this in any meaningful way. Apart from rural-urban disparities, we also noted marked regional disparities for skilled delivery. The three Northern regions, which have the lowest prevalence of the outcome, are mostly rural, with low wealth class status, lower levels of education and are predominantly Muslim compared with the rest of the population. These factors are among our significant predictors of the outcome.

Contextual issues also come into play. The observed influence of spousal education emphasises the role of an environment of high literacy on maternal outcomes. Women who have other people, including their partners, participating in the final decision on their health have a reduced chance of having skilled attendance at delivery from our results. ANC attendance and counselling for couples could be explored as a strategy to improve knowledge of the significant others and eventually improve outcomes as has been shown for HIV/AIDS prevention interventions. ${ }^{48}$ Deliveries after the introduction of free delivery policy were observed to be less attended to by skilled professionals. This is likely to be due to the gradual regional roll out of the policy across the country, the lack of knowledge about the policy and general implementation challenges, as previously observed in studies that evaluated use of free health services. ${ }^{49} 50$

Among ANC attendants, providers of care can adequately identify women who are likely to have skilled delivery (and therefore, those who are unlikely to) using the information on their wealth status class, history of previous birth complication, health insurance coverage, rural or urban residence, and religious group. This provides an opportunity to use routinely collected data to enhance service delivery and improve health outcomes.

\section{Application of this prediction}

This prediction ability is only useful when situated within the availability of effective interventions that encourage skilled attendance at delivery. Birth preparedness is an important component of the counselling at ANC that women are expected to receive. Key components of the birth plan include recognition of danger signs, a plan for a skilled birth attendant, a plan for the place of delivery, and saving money for transport or other costs in case the need arises. ${ }^{51}$ Applying the results of our study, providers will be able to sort out ANC attendants into those who are likely to use skilled attendance at delivery and those who are unlikely to do so. Those who are unlikely can be supported during the period of pregnancy to access skilled delivery.

For example, uninsured pregnant women can be encouraged to register for health insurance at the onset of the pregnancy or whenever they sign up for ANC, so that by the time of delivery the cost of care will be covered by insurance. If need be, discussions can take place with the spouse or any significant other so that money can be set aside for any eventualities. At the community level, where home visits by community health workers are possible, women who are less likely to have the outcome can have more purposeful visits by health workers that will ensure that they improve their chances of having skilled attendance at delivery.

These predictors could form the basis of a very useful clinical decision-making tool for providers. We advocate for future validation of these predictors in a prospective study and in a health facility since all the demographic and maternal data of pregnant women attending ANC in this study are captured at ANC registration. On validation, the model can be incorporated into health facility antenatal protocols and other job aids that ensure that health workers identify and practically support pregnant women to opt for skilled attendance at delivery.

\section{Strengths and limitations of the study}

Strength of this study is the national representative sample that facilitates generalisability of the study results to pregnant women in Ghana. It also not only assesses possible associations but also considers a combination of factors that significantly predict the outcome. However, the DHS data are retrospectively collected data, and therefore has some limitations. There is the chance of 
recall bias potentially affecting results. Only surviving mothers were interviewed and this could have affected the prevalence of the outcome. Also, we were unable to study other variables that possibly influence the outcome, for which data are not available in the 2008 DHS database. Last but not the least, our results will not apply to the women who do not access antenatal care during pregnancy.

\section{CONCLUSION}

Women less likely to have skilled attendance at delivery can be identified during antenatal care using data on wealth status class, health insurance coverage, residence, history of previous birth complication and religion, and can be targeted with interventions to improve skilled attendance at delivery.

\section{Author affiliations}

${ }^{1}$ Julius Global Health, Julius Center for Health Sciences and Primary Care, University Medical Centre Utrecht, Utrecht, The Netherlands

${ }^{2}$ School of Public Health, University of Ghana, Legon, Ghana

${ }^{3}$ Research and Development Division, Ghana Health Service, Accra, Ghana ${ }^{4}$ Department of Health Policy Planning and Management, School of Public Health, University of Ghana, Legon, Ghana

${ }^{5}$ Faculty of Health Sciences, Division of Epidemiology \& Biostatistics, School of Public Health, University of the Witwatersrand, Johannesburg, South Africa

Acknowledgements The authors gratefully acknowledge technical support from the Julius Center for Health Sciences and Primary Care.

Contributors MA-C designed and wrote up the study protocol, acquired permission from Measure DHS to use data, carried out data analysis, wrote the report and drafted this manuscript for publication. GAK, IAA, DEG, EKA and KK-G provided scientific guidance and did review of the study design, data analysis, and were also actively involved in the preparation and review of the manuscript and approved it.

Funding Funding for the conduct of the study was from the Netherlands Organization for Scientific Research (NWO) Global Health Policy and 396 Health Systems Research Program, the Netherlands (Grant number: 07.45.102.00). They supported authors MA-C and GAK as PhD candidates.

Competing interests Authors MA-C and GAK had financial support from the Netherlands Organization for Scientific Research (NWO) Global Health Policy and 396 Health Systems Research Program, the Netherlands, for the submitted work.

Provenance and peer review Not commissioned; externally peer reviewed.

Data sharing statement Secondary data were used for this study. These data are public and freely available to anyone from MEASURE DHS, on request. The website for MEASURE DHS is http://dhsprogram.com/data/ available-dataset.cfm.

Open Access This is an Open Access article distributed in accordance with the Creative Commons Attribution Non Commercial (CC BY-NC 4.0) license, which permits others to distribute, remix, adapt, build upon this work noncommercially, and license their derivative works on different terms, provided the original work is properly cited and the use is non-commercial. See: http:// creativecommons.org/licenses/by-nc/4.0/

\section{REFERENCES}

1. WHO, UNICEF. Countdown 2015 Maternal, Newborn and Child survival. Building a future for women and children. The 2012 report 105. 2013. http://www.countdown2015mnch.org/documents/ 2012Report/2012-complete-no-profiles.pdf
2. Bhutta ZA, Chopra M, Axelson H, et al. Countdown to 2015 decade report (2000-10): taking stock of maternal, newborn, and child survival 106. Lancet 2010;375:2032-44.

3. Magoma M, Requejo J, Campbell OM, et al. High ANC coverage and low skilled attendance in a rural Tanzanian district: a case for implementing a birth plan intervention 92. BMC Pregnancy Childbirth 2010;10:13.

4. Hogan MC, Foreman KJ, Naghavi M, et al. Maternal mortality for 181 countries, 1980-2008: a systematic analysis of progress towards Millennium Development Goal 5 3. Lancet 2010;375:1609-23.

5. Kinney MV, Kerber KJ, Black RE, et al. Sub-Saharan Africa's mothers, newborns, and children: where and why do they die? 15. PLoS Med 2010;7:e1000294.

6. United Nations. The Millennium Development Goals Report 2011. New York: United Nations, 2011. http://www.un.org/millenniumgoals/ MDG2011_PRa_EN.pdf

7. World Health Organization. Trends in maternal mortality 1990 to 2010: Estimates developed by WHO, UNICEF, UNFPA and the World Bank. 2010. http://whqlibdoc.who.int/publications/2010/ 9789241500265_eng.pdf 2-2-2012.

8. World Health Organization. Skilled birth attendants, factsheet. 67. Geneva: World Health Organization, 2008.

9. World Health Organization. Reduction of maternal mortality: A Joint WHO/ UNFPA/ UNICEF World Bank Statement 68. 2013.

10. Bergsjo P, Villar J. Scientific basis for the content of routine antenatal care. II. Power to eliminate or alleviate adverse newborn outcomes; some special conditions and examinations. Acta Obstet Gynecol Scand 1997;76:15-25.

11. Buor D, Bream K. An analysis of the determinants of maternal mortality in sub-Saharan Africa. J Womens Health (Larchmt) 2004;13:926-38.

12. Lumbiganon P. Appropriate technology: antenatal care. Int $J$ Gynaecol Obstet 1998;63(Suppl 1):S91-5

13. Tann CJ, Kizza M, Morison L, et al. Use of antenatal services and delivery care in Entebbe, Uganda: a community survey. BMC Pregnancy Childbirth 2007;7:23.

14. UNICEF. Eastern and Southern Africa Regional Office: Maternal Mortality Reduction Strategy. 2003. http://www.unicef.org/health/files/ MMreductionstrategyShoo2003.pdf 10-6-2003.

15. van Eijk AM, Bles HM, Odhiambo F, et al. Use of antenatal services and delivery care among women in rural western Kenya: a community based survey. Reprod Health 2006;3:2.

16. Villar J, Bergsjo P. Scientific basis for the content of routine antenatal care. I. Philosophy, recent studies, and power to eliminate or alleviate adverse maternal outcomes. Acta Obstet Gynecol Scand 1997;76:1-14

17. Yakoob MY, Ali MA, Ali MU, et al. The effect of providing skilled birth attendance and emergency obstetric care in preventing stillbirths. BMC Public Health 2011;11(Suppl 3):S7

18. WHO, ICM, FIGO. Making pregnancy safer: the critical role of skilled delivery. 2014. http://whqlibdoc.who.int/publications/2004/ 9241591692.pdf

19. Ghana Statistical Services, Ghana Health Service, ICF Macro. Ghana Demographic and Health Survey Report, 2008. 9 September 2009.

20. Adegoke A, Utz B, Msuya SE, et al. Skilled birth attendants: who is who? A descriptive study of definitions and roles from nine Sub Saharan African countries. PLoS ONE 2012;7:e40220.

21. Harvey SA, Blandon YC, McCaw-Binns A, et al. Are skilled birth attendants really skilled? A measurement method, some disturbing results and a potential way forward. Bull World Health Organ 2007;85:783-90.

22. Utz B, Siddiqui G, Adegoke A, et al. Definitions and roles of a skilled birth attendant: a mapping exercise from four South-Asian countries. Acta Obstet Gynecol Scand 2013;92:1063-9.

23. Stanton C, Blanc AK, Croft T, et al. Skilled care at birth in the developing world: progress to date and strategies for expanding coverage. J Biosoc Sci 2007;39:109-20.

24. WHO/UNICEF. Antenatal care in developing countries: promises, achievements and missed opportunities. Analysis of trends, levels and differentials 1990-2001. Geneva: WHO, 2003.

25. Bloom SS, Lippeveld T, Wypij D. Does antenatal care make a difference to safe delivery? A study in urban Uttar Pradesh, India 88 94. Health Policy Plan 1999;14:38-48.

26. Yanagisawa S, Oum S, Wakai S. Determinants of skilled birth attendance in rural Cambodia 90 96. Trop Med Int Health 2006;11:238-51.

27. Eades CA, Brace C, Osei L, et al. Traditional birth attendants and maternal mortality in Ghana. Soc Sci Med 1993;36:1503-7.

28. Doctor HV. Intergenerational differences in antenatal care and supervised deliveries in Nigeria. Health Place 2011;17:480-9. 
29. Nair M, Ariana P, Webster P. What influences the decision to undergo institutional delivery by skilled birth attendants? A cohort study in rural Andhra Pradesh, India 93. Rural Remote Health 2012;12:2311.

30. Okiwelu T, Hussein J, Adjei S, et al. Safe motherhood in Ghana: still on the agenda? Health Policy 2007;84:359-67.

31. UNDP. UNDP in Ghana: MDG Overview: Improve maternal health 2014 Apr 4

32. Witter S, Arhinful DK, Kusi A, et al. The experience of Ghana in implementing a user fee exemption policy to provide free delivery care. Reprod Health Matters 2007;15:61-71.

33. Asamoah BO, Agardh AF, Cromley EK. Spatial analysis of skilled birth attendant utilization in Ghana. (1916-9736 (Print)).

34. Asamoah BO, Agardh AF, Pettersson KO, et al. Magnitude and trends of inequalities in antenatal care and delivery under skilled care among different socio-demographic groups in Ghana from 1988-2008. (1471-2393 (Electronic)).

35. Measure DHS. Ghana Demographic and Health Survey 2008. http:// www.measuredhs.com/pubs/pdf/FR221.pdf. 2011. 11-12-2011.

36. UNICEF. Millenium Development Goals. 2014. http://www.unicef.org/ $\mathrm{mdg} /$ maternal.html

37. Prata N, Greig F, Walsh J, et al. Ability to pay for maternal health services: what will it take to meet who standards? Health Policy 2004;70:163-74

38. Stekelenburg J, Kyanamina S, Mukelabai M, et al. Waiting too long: low use of maternal health services in Kalabo, Zambia. Trop Med Int Health 2004;9:390-8.

39. Wall LL. Dead mothers and injured wives: the social context of maternal morbidity and mortality among the Hausa of northern Nigeria. Stud Fam Plann 1998;29:341-59.

40. Mills S, Bertrand JT. Use of health professionals for obstetric care in northern Ghana. Stud Fam Plann 2005;36:45-56.
41. Zere E, Oluwole D, Kirigia JM, et al. Inequities in skilled attendance at birth in Namibia: a decomposition analysis. BMC Pregnancy Childbirth 2011;11:34

42. Kesuma ZM, Chongsuvivatwong V. Utilization of the Local Government Health Insurance Scheme (JKA) for maternal health services among women living in underdeveloped areas of Aceh Province, Indonesia. Asia Pac J Public Health 2014. Published Online First 24 Feb 2014. doi:10.1177/1010539514524818

43. Mumtaz Z, Salway S. 'I never go anywhere': extricating the links between women's mobility and uptake of reproductive health services in Pakistan. Soc Sci Med 2005;60:1751-65.

44. Yao J, Murray AT, Agadjanian V. A geographical perspective on access to sexual and reproductive health care for women in rural Africa. Soc Sci Med 2013;96:60-8.

45. Mengesha ZB, Biks GA, Ayele TA, et al. Determinants of skilled attendance for delivery in Northwest Ethiopia: a community based nested case control study. BMC Public Health 2013;13:130.

46. Sahn DE, Stifel DC. Urban-Rural inequality in living standards in Africa. J Afr Econ 2003;12:564-97.

47. Knight J, Shi L. Educational attainment and the rural-urban divide in China. Oxf Bull Econ Stat 1996;58:83-117.

48. Farquhar C, Kiarie JN, Richardson BA, et al. Antenatal couple counseling increases uptake of interventions to prevent HIV-1 transmission. J Acquir Immune Defic Syndr 2004;37:1620-6.

49. Mills S, Williams JE, Adjuik M, et al. Use of health professionals for delivery following the availability of free obstetric care in northern Ghana. Matern Child Health J 2008;12:509-18.

50. Quaye RK. Paying for health services in East Africa: a research note. Soc Theory Health 2004:2:94-105.

51. Kakaire O, Kaye DK, Osinde MO. Male involvement in birth preparedness and complication readiness for emergency obstetric referrals in rural Uganda. Reprod Health 2011;8:12. 